\section{ANGIOTENSIN CONVERTING ENZYME GENE POLYMORPHISM IN INDIAN CHILDREN WITH STEROID SENSITIVE NEPHROTIC SYNDROME}

PATIL S. J., GULATI S. ${ }^{1}$, KHAN F., TRIPATHI M., AHMED M., AGRAWAL S.

\section{ABSTRACT}

CONTEXT: Nephrotic syndrome is one of the commonest renal problem encountered in children. It is difficult to predict at onset, the clinical course in terms of steroid responsiveness or resistance. Angiotensin converting enzyme (ACE) gene insertion/ deletion (I/D) polymorphism has been studied as a predictor of clinical course in common multi-factorial diseases including focal segmental glomerulosclerosis. There is no study available from our country till date to find out any correlation of the steroid response in idiopathic nephrotic syndrome and ACE gene polymorphism. AIM: To study distribution and correlation of ACE gene I/D polymorphism in idiopathic steroid sensitive nephrotic syndrome SETTINGS \& DESIGN: Case-control retrospective study. SUBJECTS \& METHODS: We studied ACE gene polymorphism in 90 consecutive patients ( $82 \%$ males, $18 \%$ females) with steroid sensitive idiopathic nephrotic syndrome and 300 normal controls (NC). STATISTICAL ANALYSIS: Chi-square test and Fisher's exact test (for cases with insufficient expected cell frequencies) RESULTS: The mean age of onset was $5.3 \pm 4$ years. Steroid sensitive (SS) patients showed II (SS - 48\%, NC $26 \%)$ genotype was more frequent than normal controls $(p=0.002)$. There was no significant difference in genotype frequencies among steroid SS subgroups. CONCLUSIONS: In our study II genotype was more frequent in steroid sensitive nephrotic syndrome children in comparison to normal controls. Further functional studies with large number of children are required to investigate the role of II genotype in steroid sensitive nephrotic syndrome. Comparison of the genotypic frequency with steroid resistant patients may provide information, which might be useful in clinical practice.

KEY WORDS: ACE gene polymorphism; Steroid-sensitive nephrotic syndrome; Idiopathic nephrotic syndrome.

\section{INTRODUCTION}

Idiopathic nephrotic syndrome is one of the commonest renal problems in children encountered in day-to-day nephrology practice. These children can be categorized into well-defined categories based on the response to standard prednisolone therapy. ${ }^{[1,2]}$ Majority (>95\%) of these children have steroid sensitive nephrotic syndrome (SSNS). Steroid responsiveness appears to be the single most important clinical parameter in differentiating patients of primary nephrotic syndrome and is of even greater significance than the histological features on initial biopsy. ${ }^{[3,4]}$ It is however, difficult to predict at onset the course of the disease in a particular child in terms of steroid responsiveness (SS) or steroid resistant (SR)

Various genetic markers have been studied to predict susceptibility and course of nephrotic syndrome. Increased activity of angiotensin-II alters variety of growth factors and has been shown to have detrimental effect on renal disease progression including focal segmental glomerulosclerosis (FSGS). ${ }^{[5,6,7,8]}$ These studies suggest that angiotensin converting enzyme (ACE) genotype could be one of the risk factor for the development and progression of renal disorders or indicate genetic tendency towards the disease. The data regarding the association of insertion/deletion (I/D) polymorphism and prevalence of nephrotic syndrome is scant and contradictory ${ }^{[5,8]}$ There is no study till date that has studied the relationship between ACE gene polymorphism and steroid response subgroups. Hence this study was conducted to analyze the distributions of ACE gene polymorphism in steroid sensitive idiopathic nephrotic syndrome and compared with normal controls. We also studied the distribution of ACE gene polymorphism among SS subcategories.

\section{PATIENTS AND METHODS}

We have studied 90 consecutive children with idiopathic nephrotic syndrome who were steroid sensitive and were on follow up from 2003-2004. A written informed consent was taken from their parents and the ethics committee of the institute approved the study. All cases fulfilled the International Study of Kidney Disease in Children criteria, for the diagnosis of nephrotic syndrome. ${ }^{[1]}$ The inclusion criteria were (i) age of onset more than one year and less than 18 years (ii) normal renal functions (iii) regular follow up period for minimum of 1 year (iv) good compliance with steroids.

We excluded children with (i) secondary nephrotic syndrome (ii) familial cases (iii) HbsAg, HCV, HIV seropositivity.

At presentation, they were evaluated clinically for hypertension, hematuria, anthropometric parameters (height, weight, and body surface area) and systemic involvement. They were investigated for confirmation of nephrotic syndrome, exclusion of secondary causes, $\mathrm{HbsAg}$, and HIV seropositivity, and renal function status. They were treated with steroids according to the protocol defined in our earlier study. ${ }^{[1]}$ Cyclophosphamide was administered in frequent relapser (FR); steroid dependent (SD) cases with steroid side effects, when consent was obtained. Cyclophosphamide was given orally in a dose of $2.5 \mathrm{mg} / \mathrm{kg} / \mathrm{d}$ for 3 months or in monthly pulses of $500 \mathrm{mg} / \mathrm{m}^{2}$ administered intravenously for 6 months. ${ }^{[9]}$ Based on the steroid response pattern, nephrotic children were categorized on last follow-up into infrequent relapser (IFR), FR and 
SD. ${ }^{[1]}$ Blood sample was obtained for ACE gene analysis. Three hundred normal controls (NC) belonging to North India (Uttar Pradesh), who were ethnically matched to nephrotic syndrome patient group were included for the comparisons. There was no history of nephrotic syndrome or any other renal disease among controls and also in their first-degree relatives.

\section{CASE DEFINITIONS}

Proteinuria was considered to be in the nephrotic range when the urine protein is $3+1$ $4+$ on a dipstick test, spot protein/creatinine ratio $>2 \mathrm{mg} / \mathrm{mg}$, or urine albumin $>40 \mathrm{mg} / \mathrm{m} 2$ per $\mathrm{h}$ (on a timed sample). Remission was defined as urine spot protein/creatine of $<0.2$ or absence of proteinuria on routine analysis. ${ }^{[1]}$ Steroid sensitive patients were further grouped into frequent ( $>2$ or more in 6 months or $>3$ or more relapses in a year), infrequent $(<2$ in 6 months or $<3$ relapse in a year), steroid dependent (relapse with switch of steroid to alternate day/tapering regime or within 2 weeks of steroid withdrawal).[1]

\section{MOLECULAR METHODS FOR ACE}

\section{GENOTYPE}

Genomic DNA was extracted from peripheral leukocytes by standard salting out method. ${ }^{[10]}$ PCR amplification was done using two set of primer: sense oligo 5' CTGGAGACCACTCCCATCCTTTCT 3' and anti-sense oligo: 5' GATGTGGCCATCACATTCGTCAGAT 3' in a final volume of 15 ì. Final volume of $15 \mathrm{ul}$ containing $1 \mathrm{X}$ buffer (Banglore Genei, India $B G), 1.5 \mathrm{mM} \mathrm{MgCl}, 0.1 \mathrm{mM}$ dNTPs (BG), 5 pmoles of each primer and $1 \mathrm{U}$ Taq polymerase (BG).
PCR conditions were $94^{\circ} \mathrm{C}$ initial denaturation for $10 \mathrm{~min}$ and then 30 cycles with denaturation at $94^{\circ} \mathrm{C}$ for $1 \mathrm{~min}$, annealing at $58.5^{\circ} \mathrm{C}$ for 1 min, and extension at $72^{\circ} \mathrm{C}$ for 2 min using a PTC-100 thermal cycler. PCR product of 490 base pair indicate homozygous for insertion (II), 190 base pair indicates homozygous for deletion (DD) and presence of both indicate heterozygosity (ID). PCR was repeated in cases with genotype $\mathrm{DD}$ to avoid misinterpretation of ID genotype as DD. PCR products were run on $2 \%$ agarose gel [Figure 1].

\section{STATISTICAL ANALYSIS}

Genotype comparisons of nephrotic syndrome cases and controls were made using chisquare test and Fisher's exact test (for cases with insufficient expected cell frequencies). In the second stage the ACE genotype were compared in between steroid response categories. A $p$ value of less than 0.05 was accepted as significant. All statistical analyses were performed using the statistical package for social science software package. ${ }^{[11]}$

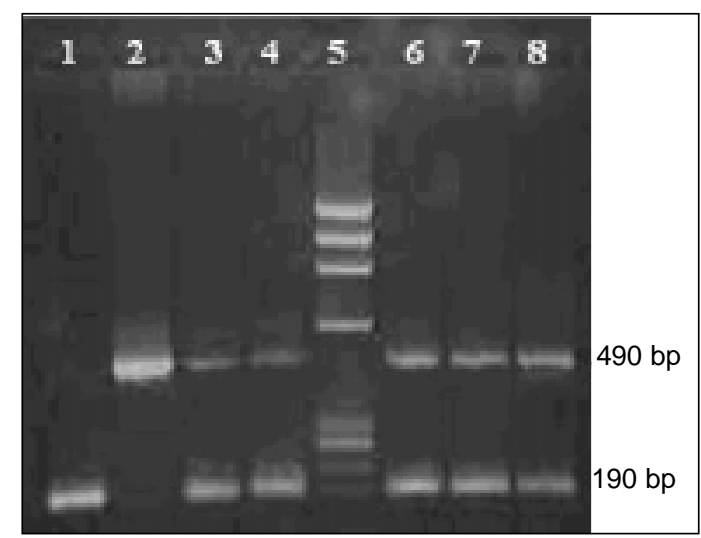

Figure 1: Lane 1: Homozygous sample (DD) Lane 2: Homozygous sample (II) Lane 3-4, 6-8: Heterozygous sample (ID) Lane 5: DNA ladder ( $\$ 174$ Haell digest)

\section{RESULTS}

The study group consisted of 90 children (82\%boys, $18 \%$ girls), with mean age of $5.3 \pm$ 4 years at the onset of nephrotic syndrome. The mean serum protein and serum albumin at disease onset were $49.7 \pm 2.2 \mathrm{~g} / \mathrm{L}$ and $23 \pm 1.6 \mathrm{~g} / \mathrm{L}$ respectively. The mean baseline serum Creatinine was $0.74 \pm 0.03 \mathrm{mg} / \mathrm{dl}$. Of the 90 children 47 children were infrequent relapsers, 29 were frequent relapsers and 23 were steroid dependent.

The details of genotype frequency are shown in [Table 1]. Allele frequency of control and normal patients are in Hardy-Weinberg equilibrium. In the steroid sensitive patients II genotype (SS - 48\%, NC - 26\%) was more frequent as compared to ID and DD genotype when compared with normal controls $(p=0.0002)$ (Degree of freedom $=1$ ) $(\mathrm{OR}=2.604,95 \%$ confidence interval=1.5994.240). The distribution of the different genotypes among the steroid sensitive subgroups [frequent relapser $(n=20)$, infrequent relapser $(n=47)$, steroid dependent $(n=23)]$ was also evaluated. There was no significant difference in genotype frequencies in steroid sensitive subgroups.

\section{DISCUSSION}

ACE gene DD polymorphism has been studied in various disorders like diabetic nephropathy, myocardial infarction and IgA nephropathy. $[3,11,12,13]$ DD genotype has been postulated as a risk factor in renal diseases. DD genotype has been shown to be associated with FSGS with declining renal function. ${ }^{[14]}$ In a study by Lee et $\mathrm{al}^{[8]}$ the frequency of DD genotype in minimal change nephrotic syndrome (MCNS) was similar to controls. However, it was significantly higher in children with FSGS as compared to MCNS. Further this study included both children and adults with nephrotic syndrome. In contrast Oktem et al..$^{[5]}$ observed that the DD genotype was more frequent in children with SSNS as compared to controls. The frequency of DD genotype in our study however was similar in SS patients as compared to controls. This is consistent with results by Lee et al. ${ }^{[8]}$ Whereas II allele was more frequent in SS patients than in controls. This appears to be a marker predictive of steroid responsiveness. We have analyzed the distribution of all genotype frequencies in steroid sensitive subgroups and there was no significant difference. This suggests that genotype frequency does not alter with the severity of disease among steroid sensitive subgroup patients. DD allele has been shown to be associated with declining renal function in FSGS patients. ${ }^{[5]}$

DD allele is known to be associated with high (60\% higher) levels of ACE than those with II allele. ${ }^{[15]}$ ACE converts angiotensin I to angiotensin $\mathrm{II}$ in the renin-angiotensinaldosterone system. This increased activity is due to increased ACE level in certain population. Plasma ACE levels depend on the genotype of ACE gene Alu-insertion/deletion polymorphism. ${ }^{[15]}$ ACE gene locus is on chromosome 17q32. Two hundred eighty seven base pairs fragment Alu-insertion in introns 16 of ACE gene decides the genotype. The mechanism causing high levels of ACE in $\mathrm{DD}$ allele is not known. A higher concentration of angiotensin-II in DD genotype is thought to cause progressive renal disease. Acting 
through various growth factors, angiotensin-II has been postulated to cause structural changes in renal system and alteration of renal hemodynamics. ${ }^{[6,7]}$

In our study II genotype was more frequent in steroid sensitive nephrotic syndrome children in comparison to normal controls. Further functional study with large number of children is required to investigate the role of II genotype in steroid sensitive nephrotic syndrome. Further comparing genotype frequency with steroid resistant patients might give better understanding of the pathophysiology of nephrotic syndrome, which might be useful in clinical practice.

\section{REFERENCES}

1. Gulati S, Kher V, Sharma RK, Gupta A. Steroid response pattern in Indian children with nephrotic syndrome. Acta Paediatr 1994;83:530-3.

2. Bagga A, Srivastava RN. Nephrotic Nephrotic syndrome and proteinuria. Indian $\mathrm{J}$ Pediatr 2002;69:1053-4

3. Nash MA, Edelmann Jr CM, Bernstein J, Barnett JL. The nephrotic syndrome. In: Pediatric Kidney Disease, $2^{\text {nd }}$ Edn. Eds. Edelmann Jr CM. Little Brown and Co: Boston; 1992. p. 1247-66.

4. Bagga A, Srivastava RN. Nephrotic syndrome in children. Indian J Med Res 2005;122:13-28

5. Oktem F, Sirin A, Bilge I, Emre S, Agachan B, Ispir T. ACE I/D gene polymorphism in primary FSGS and steroid-sensitive nephrotic syndrome. Pediatric Nephrology 2004;19:384-9

6. Matsusaka T, Hymes J, Ichikawa I. Angiotensin in progressive renal diseases: theory and practice. J Am Soc Nephrol 1996;7:2025-43

7. Navis G, van der Kleij FG, de Zeeuw D, de Jong
PE. Angiotensin-converting enzyme gene I/D polymorphism and renal disease. $\mathrm{J}$ Mol Med 1999;77:781-91

8. Lee DY, Kim W, Kang SK, Koh GY, Park SK. Angiotensin-converting enzyme gene polymorphism in patients with minimal change nephrotic syndrome and focal segmental glomerulosclerosis. Nephron 1997;77:471-3

9. Gulati S, Pokhariyal S, Sharma RK, Elhence R, Kher V, Pandey CM, et al. Pulse cyclophosphamide therapy in frequently relapsing nephrotic syndrome. Nephrol Dial Transplant 2001;16:2013-7

10. Miller SA, Dykes DD, Polesky HF. A simple salting out procedure for extracting DNA from human nucleated cells. Nucleic Acids Res 1988;16:1215.

11. SSPS for windows: base system user's guide, release 9.0. SSPS: Chicago.

12. Bantis C, Ivens K, Kreusser W, Koch M, KleinVehne N, Grabensee B, et al. Influence of genetic polymorphisms of the renin-angiotensin system on IgA nephropathy. Am J Nephrol 2004;24:258-67

13. Ozen S, Alikasifoglu M, Saatci U, Bakkaloglu A, Besbas N, Kara N, et al. Implications of certain genetic polymorphisms in scarring in vesicoureteric reflux: importance of ACE polymorphism. Am J Kidney Dis 1999;34:140-5.

14. Sayed-Tabatabaei FA, Schut AF, Vasquez AA, Bertoli-Avella AM, Hofman A, Witteman JC, et al. Angiotensin converting enzyme gene polymorphism and cardiovascular morbidity and mortality: the Rotterdam study. J Med Genet 2005;42:26-30

15. Rigat B, Hubert C, Alhenc-Gelas F, Cambien F, Corvol P, Soubrier F. An insertion/deletion polymorphism in the angiotensin I-converting enzyme gene accounts for the half the variance of serum enzyme levels. J Clin Invest 1990;86:1343-6 